\title{
US plans for weapons labs 'have ignored alternatives'
}

Washington. Environmental and disarmament groups say they will take legal action to force the US Department of Energy (DoE) to revise a blueprint for the future of its nuclear weapons complex that was released in Washington last week. They argue that alternatives - including reducing the size of the complex - have not been fully explored.

The five-volume document is known as the Stockpile Stewardship and Management Programmatic Environmental Impact Statement. It essentially backs decisions already announced by DoE. These include building the National Ignition Facility, a \$1.1-billion megalaser for weapons physics experiments, at Lawrence Livermore National Laboratory in California and establishing a capability for manufacturing plutonium weapon 'pits' at Los Alamos National Laboratory, New Mexico.

The document was printed in September, but was released only last week, leading to suggestions that publication was delayed until after the US elections. DoE officials deny this, arguing that the extra time was needed to respond to public comments and to consider the possibility of lawsuits.

According to Victor Reis, assistant secretary for defence programmes, the agency is confident it can withstand a legal challenge. But he accepts that an extended court fight could cause delays in implementing the $\$ 40$ billion, 10-year plan. "We feel comfortable we've covered all the issues [that are required under the National Environmental Policy Actl," Reis says. "We feel we are in a good position if we are sued."

But the Military Production Network (MPN), an umbrella group of environmental and disarmament organizations, says the analysis has failed properly to consider alternatives, as required under the act. More than 100 such groups threatened to sue $\mathrm{DoE}$ last May, after release of the draft impact statement, and the agency's proposed course of action did not change in the final version of the document. MPN says a lawsuit is likely to be brought by the end of the year.

Christopher Paine, senior research associate with the Natural Resources Defense Council, the group that plans to lead the litigation, argues that, to meet the act's requirements, the department must consider alternatives, such as reducing the size of the network of weapons laboratories. Only last year President Bill Clinton ordered continuation of the present three-lab structure.

The consolidation alternative should especially have been explored in view of last year's recommendations from a DoE advisory panel, the Galvin Task Force, which proposed phasing out the weapons programme at Livermore, adds Daniel Kerlinsky, president of Physicians for Social Responsibility of New Mexico, and a Galvin panel member.

But Steve Guidice, assistant manager for energy science and technology at DoE's Albuquerque Operations Office, the official in charge of the impact statement, replies that the department did not consider reducing the size of the laboratory complex to be a "reasonable" alternative within the meaning of the act. This is particularly so given the department's need for greater quantities of physics data to guarantee a continued safe and reliable stockpile without testing.

Paine complains that the DoE has arbitrarily excluded from examination many of the components of its existing stockpile stewardship programme, either by classifying them as part of its 'no-action' alternative, or defining them as 'next-generation' facilities.

But Guidice says that plans for the latter facilities, which include an Advanced Hydrotest Facility and a High Explosive Pulsed Power Facility, were considered "not mature enough".

David Kramer

\section{Universities approve hospital merger}

San Francisco. Merger of the hospitals of Stanford University and of the University of California in San Francisco (UCSF) was approved last week by the authorities at both universities.

The two schools will continue to operate independent research laboratories and medical schools, but are likely to carry out more collaborative projects, according to Gerhard Casper, president of Stanford.

Each medical school is contributing $\$ 8.5$ million to help start up a nonprofit corporation, UCSF Stanford Health Care, which will run the two Stanford and two
UCSF hospitals. The controversial merger, which will combine the University of California's public assets with the private Stanford enterprise, emerged out of difficulties both schools have experienced in the highly competitive 'managed care' environment in California.

University officials say that the merged schools will remain competitive and able to finance their extensive research operations. The plan must still undergo legal scrutiny by the state attorney general and will face strong opposition from unions representing UCSF's 4,940 employees.
Greater exchange of scientists backed for Asia-Pacific

Seoul. Governments in the Asia-Pacific region have agreed to encourage mobility and exchange of scientists between their countries, and to stimulate creativity by promoting an appropriate social environment for the advancement of science and technology.

The agreement was reached by science ministers attending the second Asia-Pacific Economic Cooperation (APEC) forum in Seoul last week. APEC, which held its first forum for science ministers in Beijing last October, brings together a number of Asian countries, together with Australia, New Zealand, Chile, Canada, Mexico and the United States.

The meeting did not spell out how these goals are to be achieved. But the Seoul declaration, signed by 18 member countries, will give science ministers a useful tool to lobby for programmes to fit these aims.

The exchange of scientists is at present limited between many of the Asian countries in APEC, which include China, Korea, Japan, Taiwan, Hong Kong, Brunei, Thailand, Singapore, Malaysia, the Philippines, Indonesia, and Papua New Guinea. The ministers recommended a region-wide study of the existing obstacles to exchange.

The declaration also calls for greater sharing of national facilities, and increasing the flow of information between member countries through, for example, computer networks and web sites on the Internet. Some steps to encourage information flow have already been taken following the Beijing conference. For example, the APEC S\&T Web, a web site that puts together a Japan-Korea project on information flow and Australia's APEC web site, was demonstrated at the meeting.

Korean officials announced plans for an Advanced Science and Technology Network (ASTN) that includes a research manpower training programme for researchers of developing economies in APEC. The network will be centred on the Korea Advanced Institute of Science and Technology (KAIST) in Taejon science city, and will open next September.

Other elements are a postdoctoral research programme for young scientists; the sharing of advanced research facilities, for example at KAIST, Pohang University of Science and Technology in South Korea, and institutions in Japan, such as the Institute of Physical and Chemical Research; and an APEC science and technology information network. The ASTN secretariat will be based at KAIST, and the Korean government aims to have it fully operational by June 1998. David Swinbanks 